\title{
Think globally - act locally
}

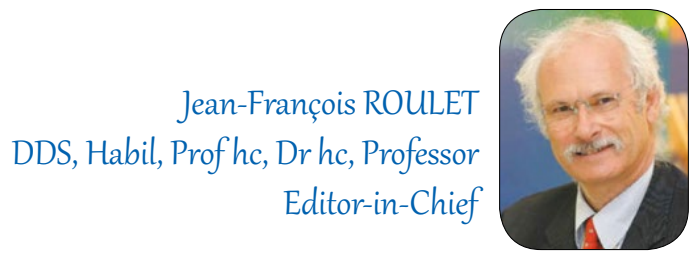

Dear Readers,

A very positive effect of the globalized information streams is that everybody willing to know what is going on can be very well informed. If you stick to facts rather than believe opinions, an analytic mind can infer from the information available that local actions usually have global effects. The global distribution of pollutants is quite easy to understand, since the weather is quite a global system. I remember two clear examples.

When 1 was a student, 1 think it was in 1969, I saw a huge tube leaning on the side of the Institute of Physics at the University of Bern. Curious 1 went to the people working on it and asked them what it was for. They explained to me that the tube was supposed to melt through the ice of Antarctica and that they would take water samples at different depths.

Due to the radiocarbon method, they were able to date the samples. Later 1 learned that with that device they could find soot that was correlated to the first industrial revolution in Europe in the late 180o's. Another example is the worldwide distribution of nuclear isotopes.

1 remember that in the 1950's, when the US was exploding Hydrogen bombs on atolls in the Pacific, it was not allowed to collect rain water for drinking purposes in Switzerland, due to nuclear pollution. The same happened after the 1986 nuclear accident in Chernobyl. $40 \%$ of the surface of Europe were contaminated with more than $4 \mathrm{kBq} / \mathrm{m}^{2}$. Radionuclides traceable to the reactor of Chernobyl were found in all countries of the northern hemisphere.

Another good example is business. Since today's business is interlinked worldwide, every national decision (e.g. tariffs, import/export restrictions etc.) will globally affect the people of other nations.

1 claim that dentistry is not different and further more 1 even claim that this is what makes dentistry that interesting. We dentists are dealing with more than teeth. My teacher and mentor Prof. André Schroeder used to say: "To every tooth there is attached a human being!" Isn't this a wonderful way to say that the teeth we are concerned with are part of the very complex machinery of the human body?

This is especially true with the ageing population we are faced with today, in combination with successful prevention. This means that the mainstream work of dentists moves from repairing single teeth to treating oral diseases or doing complex reconstructions. Whatever we do, we must consider the individual as a whole that has carried his/her teeth to our office. To understand what has lead to the situation the patients present, we need to know all the general health problems that are associated with the patient, the patient's habits and wishes, we need to understand the individual oral functions the patient has or has gotten adapted to. Remember that a faulty occlusion may lead to severe muscle pain in the neck and back, which may get chronical, with severe consequences for the patient. 
Medication-releated xerostomia will severely increase the caries risk of a patient; an allergic reaction after a local anesthesia can end up with a life-threatening situation and finally we all know that there are strong correlations between periodontal disease and general health.

Furthermore, we need to understand the materials and techniques we use and so on.

No wonder, as 1 learned from Prof. Marcello Kalabata, that 90\% of the errors that compromise a final treatment result are committed in the treatment planning phase.

This is what makes dentistry so thrilling. Despite the fact that Dentistry has evolved into a cluster of specialization, when we act locally in our specialty, we need to think globally like the "oumo universale", the ideal of Renaissance!

Sincerely yours,

J-F Roulet ${ }^{(\mathbb{O}}$

Editor-in-Chief

\section{References}

1. Sources and effects of ionizing radiation. United Nations Scientific Committee on the Effects of the Atomic Radiation. Volume II. New York, NY: United Nations Publication; 2011. [updated 2019 May 10; cited 2019 June 06].

Available from: http://www.unscear.org/docs/reports/2008/11-80076_Report_2008_Annex_D.pdf 